\title{
Atitude transdisciplinar nos procesos do ensino e da aprendizagem no ensino
}

\section{fundamental}

\section{Transdisciplinary attitude in the processes of teaching and learning in elementary school}

\author{
Sueli Perazzoli Trindade \\ Professora docente do Ensino Superior da Unoesc, do Ensino Fundamental e Médio na rede pública e particular e coordenadora do PIBID
}

\begin{abstract}
Resumo
O presente estudo teve como objetivo compreender como a atitude transdisciplinar se relaciona nos processos do ensino e da aprendizagem significativa e sensível ao religar os saberes nas diferentes áreas do conhecimento. Na concepção das professoras e alunos consideraram a pesquisa relevante no ensino e na aprendizagem ao repensar e refletir as práticas pedagógicas; as leituras contextualizadas para a compreensão da complexidade e transdisciplinaridade; a articulação dos conteúdos entre e para além das disciplinas e o diálogo centre as áreas do conhecimento, sendo assim, a escola vai continuar com a proposta nos próximos anos.

Palavras-chave: transdisciplinaridade; pensamento complexo; ensino; formação continuada.
\end{abstract}

\begin{abstract}
The present study aimed to understand how the transdisciplinary attitude relates in the processes of teaching and learning meaningful and sensitive to re-bind knowledge in different areas of knowledge. In the design of the teachers and students considered relevant research in teaching and learning to rethink and reflect the teaching practices; contextualized readings for the understanding of the complexity and transdisciplinarity; the articulation of the content between and beyond disciplines and dialogue centre the areas of knowledge, therefore, the school will continue with the proposal in the next few years.
\end{abstract}

Keywords: Transdisciplinarity; complex thinking; teaching; continuing education.

A atitude transdisciplinar no ensino e aprendizagem enfatiza a contextualização de teorias, reflexões e ações nas práticas pedagógicas, a fim de repensar e ressignificar a educação, pautada na consciência da complexidade. Sendo assim, é necessário que o professor compreenda a teia das relações existente entre sujeito e objeto, consequentemente, no aprender a aprender o professor transforma seu pensamento em uma prática pedagógica que contribui na aprendizagem significativa do aluno. Nessa compreensão, sentimos a necessidade de oportunizar aos professores e alunos estudos e ações que proporcionem a ressignicação do ensinar e aprender articulados às diferentes áreas de conhecimento, nas práticas pedagógicas.

Esse estudo foi desenvolvido por meio de uma pesquisa qualitativa de abordagem participante, com o objetivo de compreender como a atitude transdisciplinar se relaciona nos processos do ensino e da aprendizagem no Ensino Fundamental. A pesquisa foi desenvolvida em uma escola da rede estadual de Santa Catarina no Brasil, no quarto ano do Ensino Fundamental, a qual envolveu duas professoras titulares e seus alunos. A coleta de dados ocorreu mediante entrevistas semiestruturadas com as professoras e 20\% dos alunos; grupos de estudos com as professoras; diário de campo; e atividades de ensino planejadas coletivamente a partir da atitude transdisciplinar.

Complexidade e transdisciplinaridade: a contextualização dos saberes nos processos do ensino e da aprendizagem

Em virtude da existência de um ensino e aprendizagem fragmentado que isola o objeto do seu contexto natural, organizado na separação e acumulação de saberes, torna-se necessária a religação das disciplinas e a contextualização da singularidade para a construção do conhecimento significativo. A partir desse cenário do ensino, inicia-se a estimulação do desenvolvimento da aptidão para contextualizar e globalizar os saberes que se torna um imperativo da educação (Morin, 2005). Para tanto, é necessário ter como princípio a transformação e a transposição nas fronteiras do conhecimento, por meio da organização que liga os saberes em sua diversidade contextual.

A atitude transdisciplinar nos processos do ensino e da aprendizagem ocorre quando o aluno entra em contato com o conteúdo e, por meio das atividades propostas, se estabelece a contextualização e a articulação do meio social e cultural, desenvolvendo, assim, a reconstrução dos saberes e, consequentemente, o desenvolvimento da aprendizagem significativa. Quando o professor proporciona ao aluno estudos, reflexões e ações que envolvem o contexto histórico, social e cultural, o aluno consegue ressignificar o conteúdo escolar, socializar e interagir nas vivências do cotidiano.

Segundo Freire (1996:28) o homem apreende a realidade por meio de uma rede de colaboração na qual cada ser ajuda o outro a se desenvolver, ao mesmo tempo em que também se desenvolve, por meio de uma rede de colaboração na qual a ajuda é recíproca.

A teoria da complexidade reúne, contextualiza, globaliza e reconhece o ser humano e o concreto a partir de um modelo mental sistêmico que interliga as partes, gerando novas ideias e um conhecimento com 
propriedades novas. Consequentemente, o pensamento complexo inclui a esses modelos mentais a aleatoriedade, a incerteza, a imprevisibilidade e a impossibilidade de separação entre sujeito e objeto, logo a diversidade de visões possibilita os consensos sociais sobre o ambiente que o ser humano vive.

O pensamento complexo esta por toda parte, em todas as ciências exatas ou humanas, rígidas ou flexíveis. Nas palavras de Candau e Moreira (2007), torna-se necessário repensar e reescrever o currículo nos processos do ensino e da aprendizagem de forma contextualizada e articulada, proporcionando ao aluno uma visão de mundo conectada às mais diversas particularidades do conhecimento.

A transdisciplinaridade significa ir além, traduz a ideia do transcender e ultrapassar uma forma de conhecimento. Para Nicolescu (1999), a transdisciplinaridade é uma forma de ser, de saber, de fazer e de conviver com a diversidade cultural. Ao atravessar as fronteiras epistemológicas de cada ciência, dialogamos com os saberes, sem perder de vista as particularidades do ser humano e a preservação da vida no planeta. Dessa maneira, "o desafio da transdisciplinaridade é originar uma civilização em escala planetária que, por meio do diálogo intercultural, se abra para a singularidade de cada um e para a inteireza do ser” (Morin, 2011:32).

A transdisciplinaridade nos processos do ensino e da aprendizagem significa rever a concepção e as práticas educativas na escola, e não apenas readaptar as propostas vigentes, como aquelas que estão sendo trabalhadas no cotidiano escolar. Dessa forma, é possível repensar a escola em suas partes e no todo, o que, sobretudo, permitiria redefinir o discurso e as ações sobre os saberes escolares.

Necessita-se ter como princípio a transformação, a transposição e a contextualização nas fronteiras do conhecimento, por meio da organização que liga os saberes em sua diversidade. Assim, defini-se a transdisciplinaridade como um modo de conhecimento, uma ampliação da visão do mundo, uma nova atitude, uma maneira do ser diante do saber. Etimologicamente, o sufixo "trans", significa aquilo que está ao mesmo tempo entre as disciplinas, por meio das diferentes disciplinas e além de toda disciplina, remetendo à ideia de transcendência.

As atuais habilidades e competências praticadas na maioria das instituições do ensino estão aquém do atender às necessidades do contexto dos alunos, a formação do aluno necessita ser de forma integral, ou seja, uma formação humana que oportunize o aluno a construir e reconstruir o conhecimento por meio da leitura, escrita, criatividade, reflexão, conviver juntos e socialização.

Dessa maneira, a complexidade e a transdisciplinaridade pode despertar o interesse dos professores, a fim de que percebam o que há além do seu componente curricular, ultrapassando outras áreas do conhecimento, tornando-o um ser protagonista, sujeito do saber construído na conexão das disciplinas que contribuem na construção dos saberes.

\section{A transdisciplinaridade nas práticas pedagógicas na voz das professoras e dos alunos}

Com o avanço tecnológico em todas as áreas profissionais na atual sociedade, o ser humano necessita de uma formação que integre os vários saberes para interpretar o contexto profissional e pessoal. Nesse sentido, a teoria da complexidade e a transdisciplinaridade na educação contribuem para a ressignificação dos saberes por meio da contextualização.

Na concepção de Morin (2011), o importante é criar possibilidades que viabilizem as práticas pedagógicas com um pensamento complexo, ecologizado, capaz de relacionar, contextualizar e religar diferentes saberes ou dimensões da vida. A humanidade precisa de mentes mais abertas, escutas mais sensíveis, pessoas responsáveis e comprometidas com a transformação de si e do mundo.

Sobretudo, atitude transdisciplinar no Ensino Fundamental abre perspectivas para uma nova maneira de aprender, ensinar, pesquisar, exigindo mudança de percepção e uma reforma do pensamento. Um pensamento que, ao mesmo tempo em que constrói certezas, considera também incertezas.

Para repensar e ressignificar a educação, pautada na complexidade presente em toda a realidade, necessita-se da compreensão sobre a teia de relações existentes entre sujeito e objeto. O sentido do pensar a educação está na teoria e na prática, de que tudo se liga a tudo, e no aprender a aprender que professor e alunos transcendem para além das áreas do conhecimento. De acordo com Morin (2003), mais vale uma cabeça bem-feita que bem cheia alerta para a responsabilidade do currículo e das práticas pedagógicas com vistas para uma educação que possibilite ao aluno a aprendizagem significativa.

Nesse sentido, necessita-se ressignificar a formação do aluno, situando-o como coautor do projeto de aprendizagem, como construtor de seu próprio processo de desenvolvimento, por meio da interação em ambientes colaborativos.

De acordo com Severino (2002), necessita-se de educadores que ensinem o aluno a pensar, ou seja, criar estratégias que possibilitem o gosto de pensar, de aprender de dialogar, consequentemente, o estudante pode se reconhecer como sujeito de ideias, de palavras, como uma pessoa que tem o que dizer e que pode dizer, e que será ouvida, porque tem argumentos relevantes ao contextualizar os diferentes saberes.

Nos processos do ensino e aprendizagem se faz necessária uma reflexão pedagógica que contextualize o conhecimento, no qual aluno e professor tornam-se atores do processo de ensino e sujeitos do conhecimento ao construir os saberes articulados no saber ser, fazer, conviver e aprender

Vale enfatizar que as atividades mencionadas a seguir emergiram do conteúdo do quarto ano articulado com todas as disciplinas desenvolvidas pelas professoras. De acordo a Carta da Transdisciplinaridade (1994), em seu artigo 5, “a visão transdisciplinar é resolutamente aberta na medida em que ultrapassa o campo das ciências exatas devido ao seu diálogo e sua reconciliação, não 
apenas com as ciências humanas, mas também com a arte, a literatura, a poesia e a experiência interior" (Nicolescu, 199:163).

$\mathrm{Na}$ atividade seguinte, alunos e professoras construíram um mapa conceitual, com o intuito de apresentar o conceito do ser humano no contexto atual, segundo a concepção dos alunos e também, visando a possibilidades de criar ambientes colaborativos durante a semana, a partir da linguagem escrita, oral, sonora, gestual, entre outras pertinentes nos processos do ensino e da aprendizagem no quarto ano, dessa maneira, articular os conteúdos de arte, matemática, língua portuguesa, ciências, história, geografia, filosofia, educação física.

Assim, evidenciamos que os alunos aprenderam construir um gráfico. As medidas individuais formaram o gráfico que indica o percentual da altura dos alunos da turma do quarto ano. Os alunos manifestaram-se de maneira significativa em relação à atividade, na qual deveriam fazer um desenho com o barbante que correspondesse com sua altura. O aluno A24, entusiasmo, falou: fantástico, esse desenho tem $98 \mathrm{~cm}$, porque o barbante que eu colei é a minha altura. $\mathrm{O}$ aluno A21 respondeu: o meu desenho não tem a mesma medida do teu, porque a minha é diferente da tua, mas é igual, porque eu também consegui colar o barbante certo, não faltou e não sobrou, yes!

O papel do professor consiste em programar, organizar e sequenciar os conteúdos, de forma que o aluno possa realizar tal aprendizagem, incorporando os novos conhecimentos $\mathrm{O}$ que caracteriza uma aprendizagem como sendo significativa é o fato de ela envolver o aluno em sua totalidade. Dessa forma, possibilitar ao aluno a capacidade de "reconstruir significa, pois, saber pensar, aprender a aprender para melhor intervir e inovar” (Demo, 1998:72). É sinalizada a partir da ideia de reconstruir, citada pelo autor, uma prática pedagógica significativa e sensível.

Corroboram Moraes e Navas (2010:195), o docente transdisciplinar é aquele que tenta, a partir de seus níveis de percepção e de consciência, potencializar, construir o conhecimento e acessar as informações que estão presentes nos outros níveis de realidade, mediante o reconhecimento da complexidade constitutiva da vida, que traz consigo uma visão mais unificadora e global de sua dinâmica e do funcionamento da realidade.

Enquanto professoras, percebemos que nas atividades coletivas ocorre a intervenção pedagógica, e ela contribui significativamente nos processos do ensino e da aprendizagem. Atividades contextualizadas e baseadas no interesse e na realidade dos alunos fazem com que o conhecimento adquirido transforme sua realidade e possibilite sua cidadania. Sendo assim, a escola não pode ser vista como um espaço fechado e triste, mas um lugar dinâmico no qual ocorre a aprendizagem efetiva entre professores e alunos.

A próxima atividade nos instigou a estudar as diferentes paisagens geográficas em seu contexto histórico, social e cultural, observando as principais características de cada paisagem. Para aprofundar o estudo, realizamos a leitura de imagem, fruição e produção artísticas articuladas à criação do Blog na Sala de Aula, com o intuito de estimular os alunos a pesquisar sobre o tema em diferentes áreas do conhecimento e socializar com a turma. Na disciplina de arte, criamos maquetes a partir da forma bidimensional para a tridimensional, fundamentadas nas pinturas da arte moderna, e articulamos com o conteúdo de matemática medidas de comprimento e proporção, e na disciplina de língua portuguesa cantamos a música "Planeta Azul” (Chitãozinho e Xororó, 2006). Em seguida, solicitamos aos alunos que criassem uma paródia, conscientizando a preservação do nosso planeta. Em geografia e história paisagem de cada região. E, além disso, propomos aos alunos atividades sobre a economia, o meio ambiente, a política e a estética.

Na construção da maquete em grupo, o diálogo entre os alunos representa a atitude transdisciplinaridade nos processos de aprendizagem. O aluno 2 questionou seu colega: "qual a medida do isopor da maquete?" Aluno 4 respondeu: "a profe falou: $-50 \mathrm{~cm}$ de comprimento $e$ $40 \mathrm{~cm}$ de largura, e as casas não podem ser grandes demais, e muito pequena." A aluna 7 observou: "na paisagem marítima tem mais água do que terra, ela é salgada, e não dá pra tomar!” Em seguida, perguntou à colega: "Você sabe quantos litros de água tem no mar?" O aluno 4, entusiasmado com a obra de arte do artista Vick Muniz, feita com lixo, ressaltou: "Puxa! ...Quanto lixo! Olha, as pessoas se escondem atrás do lixo! De onde vem tanto lixo? O lixo vira arte? Então, com lixo, eu posso fazer arte?" A aluna 8 percebeu a possibilidade que as maquetes apresentam na escrita de textos e perguntou: "Professora, o que vamos fazer agora com as maquetes? Vamos escrever um texto? Cada maquete pode ser um parágrafo do texto?”

Ao observarmos as falas dos alunos, constatamos que estavam totalmente envolvidos na pesquisa das atividades, e isso estava proporcionando-lhes aprendizagem contextualizada com seu entorno.

$\mathrm{Na}$ conclusão dessa atividade, o aluno ressalta a importância da transdisciplinaridade nos processos do ensino e da aprendizagem. O aluno 6 enfatizou: "eu gostei de fazer a maquete, porque é mais fácil aprender o que é tridimensional, aprendi o que é comprimento, largura, a altura, ver o tamanho das figuras que combina é legal [...] todos querem fazer alguma coisa, árvores, água, ponte, animais [...] esta paisagem é natural, porque aqui as pessoas ainda não destruiu e poluiu, então, a água é limpa, tem aves, animais e muitas árvores que é importante pra ter um ar limpo, elas filtram o ar. Aqui, escuta o canto dos pássaros, dá pra tomá banho no rio e até flores vivem dentro da água! Se nós não cuidar, essa paisagem vai desaparecer do planeta." Na concepção de Parsons (2006: 196), “Aprendizagem faz sentido para os educandos, especialmente quando a conectam com os próprios interesses, experiências de mundo e vida.”

As palavras do autor são retratadas nas falas dos alunos, a seguir. A aluna 9 relatou: “aprendi a escrever paródia com música, é legal; entendi que há muitas maneiras para escrever textos. Ficou fácil escrever a paródia, porque primeiro fizemos a leitura das obras de 
arte, depois a maquete e cantamos a música, e falamos bastante coisas das paisagens, a aula foi legal.” Já o aluno 7 ressaltou: "a nossa maquete apresenta a cidade do lixo, as pessoas fizeram tanto lixo que não tem mais espaço. O prédio tem tanto lixo que sai pelas janelas. As pessoas se mudaram e continuam fazendo lixo. $O$ planeta vai ficar assim, se as pessoas não cuidar."

Os relatos dos alunos vão ao encontro do pensamento de Morin (2011: 13), ao enfatizar que o pensamento complexo, ecologizado é capaz de relacionar, contextualizar e religar diferentes saberes ou dimensões da vida. A humanidade precisa de mentes mais abertas, escutas mais sensíveis, pessoas responsáveis e comprometidas com a transformação de si e do mundo.

É significativo mencionar a criação do Blog na sala de aula. Essa atividade estimulou os alunos a pesquisar, estudar e descobrir curiosidades sobre os temas estudados. Percebemos que as práticas pedagógicas se tornam significativas para os alunos, quando possibilitam uma aprendizagem articulada com as diferentes áreas de conhecimento.

Nessa atividade, os alunos relataram a relevância de buscar outros/novos saberes, ou seja, articular as diferentes áreas do conhecimento. O aluno 3 evidenciou: "o Blog na sala de aula é legal, porque a gente aprende mais coisas, a gente tem vontade de procurar mais informação sobre o assunto, a gente procura em revistas, livros de ciência e de história, jornais recortamos e colamos no mural, e assim aprendemos mais coisas, olhando e lendo o que os colegas trazem, é legal, porque cada grupo que trazer mais informações marca pontuação."

Vale enfatizar que, além do exposto, realizamos estudos sobre o elemento fogo e o elemento terra com o intuito de desenvolver nos processos do ensino e da aprendizagem a religação dos saberes por meio de temas em ambientes colaborativos. Sendo assim, foi possível fazer a leitura contextualizada e articular os conteúdos de todas as disciplinas do quarto ano do Ensino Fundamental

Nas articulações entre os processos do ensino e da aprendizagem, consideramos que o presente trabalho se torna relevante na ressignificação do conhecimento por meio da religação dos saberes. O ensinar e o aprender de maneira interdisciplinar transcendem as fronteiras de um saber fragmentado.

Na concepção das professoras envolvidas na presente pesquisa, houve maior interlocução entre os alunos, melhora na produção de textos e na compreensão matemática, na retenção da aprendizagem significativa, pois todo conhecimento construído em sala de aula foi contextualizado por meio da arte. Percebemos que a valorização da diversidade entre os seres humanos se torna primordial nas ações interdisciplinares, ou seja, ultrapassando os limites das ciências, sem infringir ou adulterar a essência de cada um.

A construção do conhecimento adquire forma e espaço para a criticidade, autonomia, questionamento, contribuições e interpretações diversas. As professoras e os alunos sentiram-se partícipes do processo de ensinar e aprender.

\section{Conclusão}

O desafio da educação, no tempo atual, é a formação transdisciplinar. Efetivamente, consiste tornar os conceitos trabalhados em sala de aula significativos e, assim, promover a compreensão crítica dos conteúdos, mediante relações intersubjetivas, mediadas pelo diálogo, a partir da perspectiva dialética entre as partes e o todo, que constitui o centro da pedagogia mediadora da formação de subjetividades capazes de dar conta das demandas do atual processo histórico, marcado pelas incertezas, no qual o conhecimento precisa estar sempre se reconstruindo para acompanhar as transformações tecnológicas, enfim da historicidade contemporânea.

$\mathrm{Na}$ atitude transdisciplinar, o professor e aluno são aprendentes nos processos do ensino e da aprendizagem a partir do pensamento complexo. Isso pode trazer contribuições significativas no desenvolvimento da aprendizagem contextualizada ao ligar as diferentes áreas do conhecimento na formação do ser humano. Faz compreender, também, que o ser humano não aprende apenas racionalmente, mas também com a intuição, as sensações e emoções. Consequentemente, com vistas na complexidade das relações, na auto-organização, no diálogo, na problematização, na atitude crítica e reflexiva ao repensar o ensinar e aprender.

Durante a pesquisa, percebemos que o processo é lento, porém crescente e qualitativo para as professoras e os alunos participantes, já que estes desconheciam atitude transdisciplinar. No decorrer dos encontros, notamos as transformações nos processos do ensino e da aprendizagem, os conceitos preestabelecidos foram sendo refletidos de forma que, ao final, o grupo sentia-se mais seguro e autônomo na contextualização dos conteúdos com outras áreas do conhecimento.

Evidenciamos que os alunos refletiram sobre o conhecimento construído de forma significativa e, quando incentivados e motivados a transcender o saber isolado e a articulá-lo com as diferentes áreas do conhecimento e com suas experiências reais, eles foram capazes de se tornar autores de suas produções intelectuais e emocionais contextualizadas.

Diante do exposto, trabalhar com a transdisciplinaridade no Ensino Fundamental permitiu construir uma didática diferenciada, pautada na interconexão entre as áreas do conhecimento, possibilitando ao aluno compreender o mundo na sua totalidade e, desse modo, ajudá-lo na construção do seu conhecimento e da sua autonomia.

O presente estudo não esgota todas as possibilidades de compreensão das relações dos conhecimentos da atitude transdisciplinar, é apenas uma contribuição para refletir sobre como os processos vêm ocorrendo e que outras possibilidades podem auxiliar numa intervenção pedagógica comprometida com resultados eficazes. Nesse sentido, consideramos que ainda temos muito para estudar, refletir e agir no contexto da presente temática. A transdisciplinaridade, apesar de ser um desafio aos professores, possibilita na prática educativa uma mudança atitudinal e epistemológica. 


\section{Referências}

CANDAU, Vera Maria; MOREIRA, Antônio F. B. Indagações sobre currículo: currículo, conhecimento e cultura. Brasília, DF: MEC/SEB, 2007.

DEMO, Pedro. Educar pela pesquisa. 3. ed. Campinas: Autores Associados, 1998.

FREIRE, Paulo. Pedagogia da Autonomia: saberes necessários á prática educativa. 2. Ed. São Paulo: Paz e Terra, 1996.

MORAES, Maria Cândida. NAVAS, Juan Miguel B. Complexidade e transdisciplinaridade em educação: teoria e prática docente. Rio de Janeiro: Wak, 2010.

MORIN, Edgar. A cabeça bem-feita: repensar a reforma, reformar o pensamento. 8. ed. Tradução Eloá Jacobina. Rio de Janeiro: Bertrand, 2003.
Ciência com consciência. 8. ed. Rio de Janeiro: Bertrand, 2005.

Os sete saberes necessários à educação do futuro. São Paulo: Cortez; Brasília, DF: Unesco, 2011.

NICOLESCU, Basarab. $O$ manifesto da transdisciplinaridade. Tradução Lúcia Pereira de Souza. São Paulo: Trion, 1999.

PARSONS, Michael. Currículo, Arte e cognição integrados. In: BARBOSA, Ana Mãe (Org.). Consonâncias internacionais para o ensino da Arte. São Paulo: Cortez, 2006. p. 295-317.

SEVERINO, Antônio. Educação e Transdisciplinaridade: crise e reencantamento da aprendizagem. 1. ed. Rio de Janeiro: Lucerna, 2002c. 